\title{
A new method of exploring the unconscious: results of an interdisciplinary study
}

The dynamic, complex, multi-level, multidimensional, multidirectional personality structure, of course, does not allow a person not only to realize, but also "to feel the full measure of the complexity of themselves" (Gamaleya, 2018; p. 12) - however, it is necessary to strive for this: many fields, for example, psychotherapy, psychiatry and clinical psychology, are aware of the insufficiency of such subjective tools as questionnaires (Avinun et al., 2020), (Jauk, Kanske, 2021). A new method of ATIZ psychodiagnostics ("Analysis of text and zatext") could have helped.

The problem of reconstructing the value position of the author of a literary and artistic work (based on the material of poetry) led us in 2010 to the discovery, by the method of layer-by-layer analysis of literary works, of diverse phenomena of zatext. The listener is immersed in a special reality; sometimes even his ignorance of the meanings of individual words cannot destroy the magic of the verse. What kind of information, besides rhythmic and melodic (Eidlin, 2008), do listeners extract from the sounds of the text in an incomprehensible or semi-understandable language (as it happens in childhood)? How is phonetics related to semantics, is phonetic analysis of the text exhausted by examples of onomatopoeia and anagrams?

The semantics of the text makes it very difficult, closing itself, to recreate the picture that stands behind the sound characteristics - the reality that we have called "zatext» (behind the text / below the text). This concept in a different but close meaning is considered by psycholinguistics and translation theory. It is now not realized by either the author or the readers, and the control of the zatext by a vague feeling (the result of orientation in these deep and unconscious layers of the work $^{1}$ ) sometimes it is also weakened: in cases of graphomania, among authors who neglect the artistic form for the sake of ideological content, and among readers with undeveloped taste.

The content of the author's inner work is hidden from the listener-reader and literary critic; from the outside it seems that the poet the poet has no power over his talent and too weak-willed indulges in "thinking with sounds, obeying the inertia of sounds that $<\ldots>$ is stronger than himself" (Chukovsky). But the lost ability to perceive anagrams existed at the stage of primitive thinking when creating and perceiving sacred texts ${ }^{2}$; apparently, a similar fate (gradual oblivion) befell other layers of the zatext. In the course of cultural genesis, the semantics of poetic (sacred) utterance diverged more and more from phonetics: semantics continued to be in the field of awareness of authors and listeners, and phonetics went to its periphery. Humanity has forgotten about the original "pictures - the archaic source of the text; but they lived and implicitly influenced the perception of the work.

The sound characteristics of most natural and cultural phenomena are rich, sometimes contradictory, dynamic, elusive. But if this polyphony is simplified to sensory etalons - signs, a convenient formula, a categorical grid marking characters and objects with unambiguous, extremely simple signals similar to the conditional "quack-quack" and "tu-tu" in early childhood, then the analysis of the phonogram is possible. Having analyzed the sound recording first of one particularly exciting poem (dedicated to the encounter with death), and when the experience turned out to be successful, then others, we confirmed the initial hypothesis that the sequence of sounds

\footnotetext{
${ }^{1}$ about the orientation activity, see the works of psychologist P. Ya. Galperin (Galperin, 2000) and others.

${ }^{2}$ Then people were able to perceive anagrams - taboo names of gods and heroes sprayed in the form of separate phonemes and syllables (Baevsky, 2001).
} 
expresses the deployment of certain states and actions performed both obvious and invisible in the text itself - additional characters of the poem (people, animals, mechanisms, forces of nature, etc.). The analysis of the score suggests a procedure opposite to the description of the sound portrait of the character; it is required to establish who (what) and why makes these sounds, in what relations these characters (objects, forces) are, what they are doing; finally, to guess the plot connecting all these elements (the presence of even one unidentified or "inappropriate" element does not allow us to consider the work on deciphering the zatext finished.). To identify the sound source, special markers come to the rescue - the so-called sensory etalons adopted in a particular culture: "kuka-re-ku" (conditional rooster cry), "drip-drip" (drip sounds), etc. All this needs to be sorted out by losing different versions. Be able to distinguish the whistle of an arrow from the whistle of a bullet or the singing of a bird...

Initially (when analyzing the very first poem), all three layers of the zatext appeared almost together for us, barely shining through the text; over time, the orientation in the researcher's zatext was improved and transformed: the layers not only successfully separated from the text and from each other, but also within the deepest, "archetypal" layer, the near and far planes began to clearly differ, i.e. two positions arose: "eventful" and "authorial".

Four stages of research of the text and the zatext of folklore, post-folklore, fiction of the XII-XXI centuries, essays, epistolary genre texts, etc. (in whole or in fragments - about 11,000 in total) in Russian, including translated works (from Chinese, Japanese and German) have been carried out to date, but, of course, as a phenomenon of the Russian language: for "comprehension of the deep mechanisms of language is possible only on the basis of the native" (Tolstaya). All correlations of qualities are statistically reliable, calculated using the formulas of the correlation coefficient of K. Pearson, the association coefficient of D. Yul et al.

At the third and fourth stages of the study of the zatext, the works were no longer always presented in their entirety, as in the first two stages, but in three forms: 1) in its entirety (these are very small texts: proverbs, haiku, etc.); 2) divided into fragments without any omissions of the text (small works: poems, essays, short stories); 3) selected fragments (works of medium and large volume, for example, novellas, novels, dilogies and trilogies). On the one hand, they had to contain a complete thought, image, plot, that is, they had to be completely self-sufficient tests; on the other hand, the fragments were selected taking into account their significance in the work: key passages to orient the reader in the structure and content of the work, the action of "tracing the fate of the hero" (Galperin, 1971), artistic expressiveness (implicitly influencing the emotions and feelings of the reader), the originality of the author's manner (recognizable handwriting of the writer, his know-how) and diversity.

Together, these selection principles helped to recreate the image of the work remaining in the reader's memory, its collapsed script and, possibly, some quintessence of author's and reader's meanings from the fragments obtained.

\section{Anagrammatic layer of the zatext}

Philologists recognize the relevance of the problem of the connectedness of the text at its various levels, including phonetic: "an anagram tends to actualize the meaning, not only lying inside the word, "on the other side" of the literal meaning, but also being born at the junction of lexical units capable of responding to each other, entering into "dialogical" relations" (Knyazeva, 2005; p. 103). Even Ferdinand de Saussure «admitted the existence of a text under the text, or pretext. According to his assumption, the poet, when creating a poetic work, resorts to the same phonemes as in the "keyword"» (Puzyrev, Shadrina). 
An anagram is usually considered to be a permutation of letters (sounds), by means of which another word is composed from one word. In our analysis of the zatext, the simplest case of an anagram was considered, namely: 1) words are fragments formed from the first, basic, word in the same order (i.e., as the addressees hear it), sometimes in two pronunciation variants; 2) a new word is a cluster formed by two adjacent words.

By identifying anagrams, one can trace the mechanism of "unfolding artistic utterance, respectively, meaning generation" (Knyazeva, 2005; p. 98). Modern psychology, before literary studies, begins not only to understand that it is she, "the thinnest fabric - phonica" (Ibid.; p. 99), "sends us encrypted "messages", calls, messages", with the help of which the "key to her subconscious" is selected (Tayanova, 2005; p. 408), but also to study these very keys using the method of layered analysis of the zatext. As in ancient times, an anagram allows you to hint to the reader (listener) that it is customary in society to hide: for example, it is able to "interpret the images of characters in a new way, pointing to their carnival counterparts" (Shatov, 2010; pp. 163,164). Examples of the hidden attitude to political events and persons found in the anagrammatic as well as "plot" layers of the work were presented in our very first sample (46 poems). Often this is "tyrannoclasm" under the guise of a panegyric (Kabachek, 2016).

\section{The plot layer of the zatext}

The next layer storing the author's unconscious, formed by the full phonogram of the text, was called by us a plot-like, because it no longer contained words, but dynamic pictures of life the characters' relationships, their dreams and fears, behavior in extreme circumstances and daily activities. Sometimes this layer also contradicted what the author reported in the text, i.e. it carried additional meanings - a message to readers that their consciousness and, mainly, the unconscious had to somehow decipher. (The nature of the perception of the work by readers-listeners depended both on the type of correlation between the text and the plot layer of the zatext, and on the level of reader qualification.)

The plot layer of the zatext - this is the emotional, motivational background of the work, as well as its sensual fabric - turned out to be the most difficult to decipher, but very meaningful. Standing behind the phonogram, reconstructed with the help of a union of logic and imagination (as well as a simplified "categorical grid", i.e. sensory etalons), paintings are full-blooded images of external reality that embody internal reality: the true relationships, feelings, desires and fears of the author (including those that he himself does not suspect).

This layer has characteristics that were previously attributed only to the text; it reveals not only the plot, characters (including new ones compared to the text), characteristic author's techniques - favorite motifs, metaphoricity, playing with space and time, complex "cinematic" editing, special speech characteristics of the characters, the inclusion of imaginary characters of events along with real events in the fabric, etc., but also the true author's attitude to the described, which is often hidden by the author from others and even from himself. The text can depict a conditional place and time, and the zatext is quite specific (i.e., it can be a kind of document); analysis of the poem's score helps clarify the idea and even the genre of the work (Kabachek, 2016).

\section{The "archetypal" (integral) layer of the zatext}

Its two main and interrelated functions are: harmonization and "energization" of the listener and the author, which are carried out in different formats, mutually imposed, spatial and temporal.

Melodious sounds (singing, ringing of bells, etc.) as a source of euphony have a meditative, soothing or even soporific effect, help the body recover from stress: "In this continuous, too mellifluous melody there was something relaxing the muscles" (Chukovsky); turbulent sounds - 
deaf fricative consonants (Kodzasov, Krivnova, 2001), i.e. whistling-wheezing-hissing - rustling in the grass produced by an invisible creature, fraught with a threat to our primitive ancestors (Korb, 2015), as well as aggressive sound manifestations of predatory animals: growling, hissing (Mishankina) ${ }^{3}$, barking, as well as hoof clacking (a rushing herd of ungulates can be dangerous, because it cannot stop quickly) - give, due to turbulence, an additional charge of energy, mobilizing the speaker and listener .

The ancient nature of this layer, the biological and social meaning of these two functions (expressed with the help of "heavenly" or "infernal" symbolizations assimilated in a particular cultural tradition) is obvious: 1) please the listener, "put him to sleep" and /or harmonize the communication situation, 2) show yourself more impressive, assertive and strong than it is, and, at the same time, provide yourself with the missing energy in case of conflict or complex, twodimensional communication. (The second plan is present in the game, comic communication or in the case of deception. If the player needs additional energy to hold two realities at once, then the deceiver with the help of sound turbulent (explosive) aggression is also trying to directly influence the listener, distracting him from the hidden content of the message.)

The mirror effect of artistic communication (the dialectical duality of the author and the addressee) is that the hidden code of the message, the phonogram of the work equally affects both the author of the utterance and the listener. The author, therefore, not only energizes himself, but also the listener; and not only tries to hide inconvenient and contradictory information from the listener, but also from himself. But it is impossible to hide it to the end: an artistic work, like a clot of human abilities, accumulates everything in itself $^{4}$. This gives a unique opportunity to know a person (what kind of person the author of a literary work is, how he wants to appear to contemporaries and descendants, and what is perceived or not perceived by listeners-readers).

If initially we described the personalized result of the interaction of two instances harmonizing, relaxing and activating, energizing as a type of hero of the zatext 1) naive, unreflecting folklore character, 2) conscientious hero, 3) deceiver, 4) super-being on the other side of good and evil), then further analysis of the archetypal layer of the zatext of 500 works of small folklore, children's and adult fiction (poetry and prose), as well as non-fiction texts allowed us to see behind each of these heroes - a special subjective reality in which the hero exists: 1) a reality similar to a dream (Utopia country), where everything happens without much effort of the hero, spontaneously-unpredictably; 2) the usual everyday reality; 3) the reality of the game, jokes / deception - fundamentally two-dimensional; a world where sometimes the "ability to distinguish between absolute seriousness and equally absolute irony" disappears (Agamben, 2012; p. 17); 4) the territory of power. (As well as intermediate, transitional between them and/or composite, for example, the central field 1-4 - the place of chaos / the world of order / eternity, cosmos.)

The researcher's deeper and more consistent entry into the archetypal layer of the zatext, the development of each new semantic space that has opened up, made it possible to present the inner world of the author and the nature of his interaction with the addressee as a "double code": the ratio of two realities (more precisely, positions in them): 1) the event being described; 2) the author's attitude to it. The value of the second internal, hidden position is determined by the

3 the author, of cause, writes about the conscious, not unconscious "primary differentiation of objects of the world and its structuring": the perception of "certain types of objects as dangerous (growling, hissing) or non-dangerous (squeaking) belonging to one or another sphere of reality, depending on the type of sound" (Mishankina).

${ }^{4}$ See the works of psychologist A. N. Leontiev: (Leontiev, 2005) and others. 
mentioned mirror effect of artistic communication: $\mathrm{I}=$ You (the requirements for yourself are equal to the requirements for the Other). The second (internal) position appears in the reader's ontogenesis not immediately, but as the child develops folklore and literary works (the requirement of verbatim re-reading is an indicator of this invisible work). It is clear that at first the most distinct, rich sounds of the phonogram of the zatext are available to the listener: as the practice of listening to the zatext develops, more and more new sounds of the "soundtrack" become intelligible to the unconscious child - indistinct, as well as previously incoherent, torn. Initially, the child learns the basic fields: 1, 2, 3, 4, then the intermediate ones begin to be perceived. Over time, the phonetic picture becomes even more enriched, complicated, becoming more voluminous and saturated. (Kabachek, 2016).

So, the integral layer of zatext, combining text and zatext, semantics and phonetics (Kabachek, 2016), is formed by a selective, not a complete phonogram: sounds and sound combinations of two opposite groups: A (activating, mobilizing the psyche) and R (relaxing, harmonizing the soul and body). (It is not difficult to notice that these signaling sounds and sound combinations are associated with the sympathetic and parasympathetic systems.) Additional sound stimulation helps the reader-listener to more accurately, subtly tune in to the perception and experience of the meaning of the author's message, since one or another combination of groups A and $\mathrm{R}$ of sounds and sound combinations (more precisely, their number is many, medium, small in this phonogram) directly, unambiguously - through combinatorics - leads to a completely specific semantic field of the unconscious, i.e. is their trigger.

In other words, by activating certain semantic fields of the unconscious, the author causes a certain emotional and value reaction of the listener-reader: the relationship between the nature of additional stimulation of $\mathrm{A}$ and $\mathrm{R}$ groups of sounds and the semantic field activated in humans in the structure of the unconscious is unambiguous in $89 \%$ of cases, and exceptions have a special meaning, confirming the relationship between the type of auditory stimulation and the fields of the zatext (Kabachek, 2021).

\section{Research results}

Based on the results of the study of literary-artistic - and, more broadly, speech - activity (perception and generation of text/zatext), it was possible to present the structure of the human unconscious in the form of an archetypal universal matrix (AUM) - a 3D-model of a vertical cylinder (it was in ancient times represented in Scandinavian folklore in the form of a world tree Yggdrasil - a channel to the upper and lower worlds from the middle, Midgard). At its base is a circle with eight sectors with a ninth circle in the center (this was also understood in ancient times: in the form of Ba-Gua sectors in ancient China). Each field (and with a more fractional division they can be $12+1$ ) can be perceived through one or another filter, because a color circle (with white in the central field), and, possibly, a twelve-tone sound system by A. Schoenberg (where the thirteenth, central, field is silence), a sequence of chakras, a set of neurotransmitters, and even a cosmogram (12 fields with a central, 13, field - the Earth, i.e. an ancient geocentric system) and many others can be projected onto it.

There are various routes of movement from the lower to the middle and upper registers (worlds) and vice versa, as well as various trajectories within the same register. The numbering of the four main fields (sectors) and five (including the central) intermediate fields is carried out clockwise, from left to right: "Caring" (1), "Research; cooperation" (2), "Play, humor, creativity" (3), "Survival, struggle, power" (4) and intermediate semantic fields $(1+2,3+4$, etc.) - the latter, as indicated, are formed in ontogenesis (individual development) and in cultural genesis later than the main ones. Their localization was found in the brain substrate of humans and vertebrates 
(Panksepp, 1998) (since studies were conducted on animals and young children, three fields related to such complex phenomena as research and decentralization (fields $1+2,2$ and $2+3$ ) were not yet differentiated, represented by one SEEKING field).

The generation and perception of the zatext of the work is more accurately described in the form of a code with two positions; i.e., during creativity / listening, not one, but two fields are usually activated: the first is triggered by distinct, easily identifiable sounds, the second position is formed not only by them, but also weakly distinguishable and therefore subjectively perceived as "distant", sounds and sound combinations of groups A and R. The author has them in mind as a possible development of events; this is his assessment, probabilistic forecast and attitude - a zone of choice, "a free and not predetermined by empirical necessity revelation of personality" (Bakhtin). The first position in the double set describing what is really happening now is the content of the author's message ("given, event"), and the second is a consequence of his personal attitudes: a subjectively colored picture ("meaning").

With the verbal method of activating archetypal universal matrix (AUM), developed in the course of anthropo- and cultural genesis, there is a weakening of the 4 fields ("Survival, power, struggle") due to the relative redistribution of signal A and R groups of sound combinations in favor of other fields: a manifestation of humanization.

Normally, the generation and perception of the author's message (doublet) is flexible, dynamic, "objective", and the forecast is based on real facts-signals. But this does not always happen. Three groups of pathologies of generation and perception of a doublet can be described.

I. When moving from the 1 st position to the 2 nd, an unmotivated descent into the lower case occurs. This distorts the perception of the world, generates anxiety, depression, rigidity (stagnation), irritability, and also weakens decentration (manifestations of the qualities of fields in the lower case). This is a functional and reversible phenomenon (for example, neurosis of some varieties). A mental trauma that has become dominant can "drag" down; you need to work with it.

II. There is a substitution of the 1st position of the 2nd due to the pathological hypersensitivity of a person (he perceives indistinct signals as distinct); the doublet is then either filled in the same way (twice with the 2 nd position), or instead of the 1 st position there is a 2 nd, and in place of the 2 nd there is an empty field or a "projection" field (if, in addition to the fact that neutral signals are perceived as significant, they are also filled with an important subjective meaning, often traumatic, provokes the appearance of a second personality, i.e. " splitting", or, at least, the phenomena of ambivalence and ambitendence).

If the first case (characteristic of schizoids) makes it possible to compensate for perception, then the second generates a "void" (with the second field unfilled) and/or an inverse, paradoxical, "twisted" feeling that someone else's thoughts come into my head from the outside world (the purpose of the 1st position) (the content of the 1st position is what should be in the 2nd) - the syndrome of mental automatism, or Kandinsky-Clerambault ("mine as someone else's" is interpreted by a schizophrenic as "someone else's mine"). The schizophrenic perceives his own forecast and assessment of events as imposed; they cannot be experienced as their own, being moved to another position.

At the school of Yu. Polyakov, it was proved that the probabilistic structure of past experience is violated in patients with schizophrenia: they use essential and latent signs with equal probability. These violations of selectivity are manifested not only in thinking, but also in other types of cognitive activity (Polyakov School).

The opposite variant of changing positions is when both positions of the doublet are filled with what should have been the content of the 1st position (due to weak perception or not 
perception at all of the indistinct sounds of groups A and R.). Perhaps this is characteristic of persons with intellectual disabilities.

III. The values of signals of A and/or R groups of sounds blocked during the stress of birth (with the help of some kind of conditional regulating filter-slider) continue to be not perceived or perceived weakly / inconstantly, since this hypothetical slider does not begin to expand the values of these signal sounds in the postnatal period of the child's life. Unlike the situation with healthy newborns, who gradually, even in the prenatal period, master not only the sounds of their native language (Wermke et al.), but also the signal values of the sounds of the A and $\mathrm{R}$ groups, which are reinforced hormonally - through the general blood flow - by the mother's reactions to these sounds, and then, after birth, as the "slider" expands the zone of access to these strong semantic stimuli, they are re-recognized and mastered in full.

Blocking the sounds of $\mathrm{A}$ and/or $\mathrm{R}$ groups as signaling leads to distortion of the AUM fields; for example, towards the field of No. 4 (these are shades of red), if both groups of sounds are blocked or weakened. If the tendency to descend into the lower register is added to this, then we have a picture characteristic of paranoia (psychopathy when descending to the 2nd position and paranoid schizophrenia - when descending to the $1 \mathrm{st})^{5}$. Another reason for some cases of schizophrenia is also known - destruction, violation of the integrity of the physical substrate of the AUM - amygdala (Webster et al., 2006).

If the signal sounds of the $\mathrm{P}$ group are inverted (negative) and/or there is a doubling of the 1st position, there may be perceptual disturbances of the type of Asperger syndrome. (Which does not negate the facts of the influence of mirror neuron pathology on autism.)

Of course, this hypothesis should be tested experimentally.

In addition to the speech variant of AUM, which has representation in the limbic system in the amygdala (Pankssepp, 1998), where activation of one or several fields at once (in real life or when telling about a significant situation) causes corresponding feelings and behavioral reactions, we have described another, complementary, system formed, however, by other combinations and quantitative characteristics of the same A and R groups of sounds and sound combinations (which became carriers of vital information in the process of anthropogenesis) - the narrative of the hero's fate, which also has its roots in archaic times; there are obvious traces of the influence of the seven-character scheme of the folk fairy tale by V.Ya. Propp (Propp).

Both of these systems have a double code and three registers: lower (negative), middle and higher (positive). But if the AUM is represented "topologically": as a circle with four basic semantic fields and four intermediate ones, as well as a central one, the narrative codes are rather "chronal": they are composed of triads with three possible degrees responsible for the unfolding of the "fate of the hero" (Galperin, 1971), his passage of life, his condition in certain key circumstances and his moral choice, behavior, as well as the forms of the presence of the Giver in his life. Such combinations of triads 27: they form a kind of "alphabet" of existential-psychological statuses (i.e. they show the being-in-the-world of the subject) and associated with the concept

${ }^{5}$ The preference for red by paranoid patients signals that their "psychic energy" is out of control. They become dependent on their "red states", which determine both their behavior and attitude to the environment. This means setting up an irreconcilable struggle, searching for enemies, recognizing only extreme measures and denying compromises. The "red condition" is looking for struggle and resistance, and if it does not find this in the real world, then it turns to the illusory" (Bazyma). 
(meaning) of a work/utterance. The relationship of the Hero - Giver with the structure of the text / zatext is even more important than the relationship of the Hero and the Antagonist! Also informative are individual components of triads expressing latent aggression (vitality), a sense of the absurdity of the world, emotional discomfort, as well as the presence / absence of a protective psychological filter, which, leading to a narrowing of consciousness, contributes to the emergence of an ASC (altered state of consciousness).

Of great importance are such subpersonalities as the childlike Self, based on the matrix of oral speech, and the adult Self, based on the interference of the matrices of oral and written speech (namely, on the phonetics of school speech, and not at all the academic version of phonetics). Traditionally, it is believed that the childlike Self is emotionally, intuitively, spontaneously, sincerely, appreciates variability, experiments, self-centered, dreamy and irresponsible, and the adult Self is more rational, reflective, controlling, responsible, with a strong will, appreciating stability, de-centered: sees the situation from the outside. (These are not Jungian archetypes or subpersonalities of R. Assagioli, but the grounds for some of them; they are the "inner child" and, similarly, the "inner adult". According to E. Bern, this is an Adult and a Child, according to Z. Freud, Id and Ego, more precisely, their speech equivalents.) They often differ in the characteristics of both activated AUM fields and narrative codes.

The cases of coincidence of the meanings of both I's are analyzed separately: a general characteristic of this type of personality is given, as well as an analysis of the situation of preschool-age authors (illiterate) and native speakers, where the rule "we write as we hear" is observed (using the example of the Serbian mentality). It also describes the wishes for AI developers (after all, cyborgs are still deprived of both adult and childlike Self: how can the sequential passage of the path of the hero (all the numbers/fields of narratives) of AI be organized.

Written speech, together with the indicated second, "compromise" phonetic system formed by interference, participates in the construction of another functional formation - dynamic subjectness, the levels of which show the manner of a person's feeling of himself as an independent being, a subject in a certain situation.

A change in the AUM field may lead to changes in the indicator we called the existential gap (EG), originally discovered when analyzing stories about vampires. The analysis of the zatext in the 1st position of the AUM code showed that when the characters met with a stronger and more dangerous being from the other world, one of the semantic fields described in the text fell out (there was a kind of rupture of the shell of our world, where a dangerous other invaded, outwardly similar to a person). In other genres, they were also people - class and other "enemies". When analyzing texts and zatexts related to children's subculture, a positive version of the meeting of heroes with manifestations of the otherworld was revealed: the joy of a miracle, magic or the opportunity to go to a better world. So, in the positive version, this is a transformation of the worldview, and in the negative - the loss of support.

Methods of directed influence on the emotions of others (listeners, readers) - and, yourself: 1) absolute balance (getting the sounds of group A or R, or both at the same time to the point of symmetry in the intermediate semantic fields, or the equality of their intensity in the second field of the AUM) helps the reader to tune in to the perception of the author's message as much as possible, to be attentive without straining; 2) super-balance (the same, but repeated): the author's voice is no longer loud, but rather deaf; a cry that is not a cry at all, but a mutter, a remark aside - a confession. Pushkin's formula of super-balance: "the noise of internal anxiety" ("The Bronze Horseman"). In the positive version (higher or middle registers) this is an experience of insight, and in the negative version (lower case) it is a difficult, previously repressed experience. 
The additional fields activated by signal sounds and sound combinations were also informative: they formed one or another chord. It can consist of various combinations: expansion (activated opposite AUM field - in 180 degrees), shift (activated adjacent or adjacent to the opposite field - in 45 degrees) or hit (in 90 degrees field).

So, the writer has a large arsenal of influences on the reader's consciousness and unconscious. Types of reinforcement and enrichment of meanings: 1) perceptual (expansion of vision, unexpected blow "from the side", shift of the assemblage point of perception); 2) emotional (style of the message: open aggression, bitterness, irony, different types of pathos and neutral style; hidden aggression, emotional discomfort, a sense of absurdity, as well as panic; existential gap (loss of support), super-balance (recognition); 3) value (lie or dual register, i.e. positive and negative, simultaneously); 4) energetic (absolute balance - strengthening the significance of what has been said and the presence/absence of a protective psychological filter); 5) ritual-energetic, for example, in the genre of conspiracies, affirmations, moods, mantras (areal cross, small (field 1-4), large cross - a composite figure).

Another interesting component parameter is a dream come true (CM): without ASC, hidden aggression, absurdity-illusions-lies, emotional and value discomfort, etc. - all feelings are light and philosophical, like Buddhist monks. The formula of happiness? But it turned out to be directly dependent on the values of the author (hero): it is not always light, clean, perfect. More meaningful, however, is not the CM as such, but the interspersing of a medium or strong degree of latent aggression or a sense of absurdity, etc.: this makes it possible to analyze what exactly is missing for happiness, for the realization of the cherished dream of the author (hero): his view of his life through a value filter.

The psychological characteristics of the four ontological statuses (in both I, childlike and adult) are also described in detail as additional variants of subpersonalities: 1) Harmonizer - two USC, 2) Fantasist - USC in the adult Self and ASC in the childlike Self, 3) Magus, or Player ASC in the adult Self and USC in the childlike Self, 4) Virtualist (addict, crazy, dreamer) - two ASC.

50 groups of texts (out of 200) were selected, in which integral indicators were analyzed: the ratio of $\mathrm{CM}$ and $\mathrm{EG}$ and ontological statuses. Two polar zones attracted attention: 1-5 - the zone of clarity, stability and diversity of desires (the usual filled life BEFORE the vocation of the Hero of a folk fairy tale - or AFTER); 12-16 - the "ideas-fix" zone (the only, but powerful and organizing the hero of the goal-desire) and the ontological twofold world (the hero on the way, accomplishing his mission, feats). Variants of combinations of attitudes to zones formed six large groups. The most interesting and unexpected was the 6th group - "prisoners" (victims of circumstances): some of them are able to break out of their psychological captivity (the characteristics of three large groups were compared: norm, borderline mental pathology and obvious pathology). If people with pathology complain powerlessly, then the norm has a long list of exactly what has already been rejected, overcome - a sense of trouble, loss of the path, trouble, fragility and remoteness of the native, debates about passions, mismatch of external and internal, unfinishedness and even homegrown psychotherapy. For a new life is ahead, and the past has burned down. It's like a transformation - for the strong in spirit. It's the death of the Ego. Per aspera ad astra.

The sequential increase and decrease of panic with a dosed increase in the degree of deconstruction of the text (nonsense as a stressor) has also been studied. It turned out that the exhausting and excessive, at first glance, attention of listeners (readers) in relation to a meaningless text is justified. So, in moods and conspiracies, "grids" of various types superimposed on the text 
(i.e., a situation where, for example, every first and second word is removed and only every third remains), help the unconscious to receive important information in the form of an order, suggestion.

Separately, through the prism of the zatext, pathological conditions are considered: symptoms and their correlations (fear, thinking disorders, various types of aggression - open, hidden and derogatory); as well as autism spectrum disorders and the phenomenon of synesthesia. Bipolar affective disorder interested us mainly in ways to overcome hyperthymia and depression.

In addition to three large groups (mental norm, explicit and borderline pathology), variants of personalities with developmental peculiarities and pathology (in comparison with the norm) were described: autistic, hysterical, schizoid, so-called schizo-hysterics, as well as the state of "schizo-autistic" - what they unconsciously prefer and what they avoid.

The uneasy relationships and texts of two addicts have been analyzed: I.V. Stalin and M.A. Bulgakov. The texts of the latter have been also compared with the works of I. Ilf and E. Petrov, in order to attribute the dilogy "Twelve Chairs" and "Golden Calf", which some researchers now impute to Bulgakov (Amlinsky).

Historical and political psychology were also considered through the prism of zatext: the "archaic" type (the forerunner of the intellectual of primitive times), unexpectedly revealed when analyzing the more or less uniform distribution of the qualities of "infantile", "hysterical", "autistic" and "schizoid" in the interaction of adult and childlike Self; psychology of Novgorodians and Muscovites of the XV century and internal rejection of the pro-Moscow policy by Novgorodians (by scribes of the life of Blessed Mikhail Klopsky), revealed by us when analyzing narrative codes; the change in the unconscious reactions of the liberal and conservative (proKremlin) intelligentsia during 2018-2020, as well as, separately, the deep value and psychological attitudes of the pro-Kremlin "trolls", which did not coincide with any of the versions of political scientists, have been described (Kabachek, 2021).

\section{Examples of analysis}

"How scared I am. I feel so sick. But no one will take me away from me" (V. Nabokov "Invitation to a Beheanding"). Dynamic subjectness - 7.0 (the position of the observer, not the victim or the led). AUM code: 1,1+2-1,1+2 (both adult and childlike Selves are activated in the same way: they describe caring, but they are immersed in meditation, a dream). Duplicated, respectively, and some other characteristics related to the AUM: there are identical events / feelings occurring in parallel, which strengthens them - a double existential gap and a hit (it seems that a hit is an attack of fear and nausea), but also a doubled feeling of a dream come true (CM): I found myself authentic in both of them (in the childlike and adult Self); doubled and mediumstrength directed impact on the emotions of others, i.e., conversion to the outside. A kind of silent scream or exhalation? An inner cry that turns into an exhalation, into the strength of silence. And both subpersonalities are in a normal, not an altered state of consciousness.

Narrative code: 6,9 - 5,9 (No. 5 - passions: opinions for and against, No. 6 - fragility / remoteness of the native (analogous to the "review effect" (Flint, 2018), No. 9 - affected). Observers see the weighing of opinions about passions in the adult Self and the feeling of fragility/ remoteness of the native in the childlike Self; according to self-perception, both Selves are in affect (but this is not a panic attack - then the central field 1-4 would be activated in the AUM).

A more complex example: "The candles were removed, the room was again illuminated by one lamp. The Countess sat all yellow, moving her drooping lips, swaying right and left. In her cloudy eyes, a complete absence of thought was depicted; looking at her, one would think that the rocking of the terrible old woman did not come from her will, but from the action of hidden 
galvanism" (A. Pushkin "The Queen of Spades"). Dynamic subjectness - 7.1 (observer). 11111 12111 - the adult Self has a dream come true, but in a childlike Self this is hindered by a moderate degree of hidden aggression (the rational part of Pushkin's hero Hermann rejoices that the goal is achievable: the old woman will soon be in his power, but the childlike Self is not inclined to idyll: the circumstances are scary). And both of them are in the USC.

AUM code: $1,2-1+4,2$. The adult Self is thinking about caring, about helping - but to whom: the old countess, to bring her out of unconsciousness, or to herself (with advice on how to win at cards)? The childlike Self also thinks, but more about selection (culling, removal). And again, the question to which Pushkin in this story, swirling with a mystical mood, does not give an unambiguous answer. Should Hermann removal from here: the hour is uneven, someone will look in - and then the adventure will be forever failed? The fields of AUM are highly enriched: the adult Self has an extension, a hit and two shifts of perception, and the childlike Self is a hit and three shifts. The shifts of perception superimposed on another area (projections of the AUM in the second subpersonality) just and create an atmosphere of flickering, flowing, fuzziness, fluctuation here. Throughout the work, "Reality" may turn out to be a "Dream" (a terrible dream / delirium) and vice versa: this is an artistic device of the author. "This whole story fluctuates at each of its points as at a point of choice, as if the author throws his bank card in front of us - a card to the right, a card to the left, and so on and so on" (Volkov).

Narrative code: 12.27 - 3.24. There are only subpersonalities, not circumstances: an indicator of the importance of what is happening (No. 3 - "Shadow: caring (eager for care) / instrument of Doom (evil); meeting with Fate"; No. 12 - "Psychotherapist: autobiographical memory as a derivative of psychological protection / hell and paradise of society", No. 24 "Escapist: atypical communication", No. 27 - "Finaliter: the end of a scrape; convalescent"). From the outside, one sees a fateful meeting in the adult Self and the need for a psychotherapist, psychological protection from the hell of society in the childlike; according to the self-perception, the adult Self anticipates - very prematurely! - the end of their efforts to find out the secret of the cards from the old countess, and the childlike Self is fascinated by the contemplation - the premonition of communication with a strange person.

A bright bearer of the bipolar affective disorder in life, Pushkin overcame it in his work through self-editing: he was able to correct and/or ruthlessly discard numerous variants produced by him at the stage of hyperthymia; Pushkin's contemporary writes about the work on the poem "Poltava": "then followed the finishing, in which there was not even a fourth part of the sketches. I saw his draft sheets, so stained that it was impossible to make out anything on them" (Yuzefovich).

\section{Reference}

1. Agamben, J. (2012) Open / Trans. from Italian. and German B. M. Skuratov. - Moscow : Russian State Humanitarian university, 2012. - 112 p. - (In Russ.)

2. Amlinsky, I. 12 chairs by Mikhail Bulgakov. - https://amlinskiirina.livejournal.com/1191.html - (In Russ.)

3. Avinun, R., Israel, S., Knodt, A.R., Hariri, A.R. (2020) Little evidence for associations between the Big Five personality traits and variability in brain gray or white matter https://doi.org/10.1016/j.neuroimage.2020.117092 Under a Creative Commons 
4. Baevsky, V.S. (2001) Linguistic, mathematical, semiotic and computer models in the history and theory of literature. - Moscow : Languages of Slavic culture, 2001. - 336 p. - (In Russ.)

5. Bakhtin, M.M. The problem of text in linguistics, philology and other humanities. The experience of philosophical analysis. - http://www.infoliolib.info/philol/bahtin/probltext.html (In Russ.)

6. Bazyma, B.A. Color and psyche. - http://psyfactor.org/lib/colorpsy.htm. - (In Russ.)

7. Chukovsky, K.I. Alexander Blok. - https://omiliya.org/article/aleksandr-blok-korneichukovskii - (In Russ.)

8. Eidlin, V.I. (2008) On the question of self-valuable knowledge and self-valuable actions // Psychology and School. - 2008. - No. 4. - pp. 90-101. - (In Russ.) - For the Russian magazine "Психология и школа".

9. Flint, K. (2018) Your brain on space-the overview effect. https://phys.org/news/2018-10-brain-spacethe-overview-effect.html

10. Galperin, P.Ya. (2000) Introduction to psychology: studies. manual. - 3rd ed. Moscow: Book. House "University": Yurayt, 2000. - 329 p. - (In Russ.)

11. Galperin, P.Ya. (1971) Reasonableness of actions and the subject of science // Psychological research. Tbilisi: Metsniereba, 1971. - pp. 123-131. - (In Russ.)

12. Gamaleya, G. (2018) How good it is to have your own face. https://gitr.ru/data/events/2018/gamaleya_8.pdf - (In Russ.)

13. Jauk, E., Kanske, P. (2021) Can neuroscience help to understand narcissism? A systematic review of an emerging field. By Cambridge University Press: 28 May 2021 Can neuroscience help to understand narcissism? A systematic review of an emerging field $\mid$ Personality Neuroscience | Cambridge Core

14. Kabachek, O.L. (2016) The Gateway to the Unconscious, or Nabokov +. - Kiev : Strelbitsky Multimedia Publishing House, 2016. - https://libcat.ru/knigi/nauka-i-obrazovanie/sciphilology/57045-oksana-kabachek-vrata-v-bessoznatelnoe-nabokov-plyus.html - (In Russ.)

15. Kabachek, O.L. (2021) Topos and Chronos of the Unconscious: New Discoveries. Kiev: Strelbitsky Multimedia Publishing House, 2021. https://andronum.com/product/kabachekoksana-topos-i-hronos-bessoznatelnogo-novye-otkrytiya/ - (In Russ.)

16. Knyazeva, E.A. (2005) Anagram in V. Pelevin's prose // Russian Literature of the XX century. Typological aspects of the study: Materials of the X Sheshukov readings. - Moscow: Intellect Center, 2005. - pp. 97-103. - (In Russ.)

17. Kodzasov, S.V., Krivnova, O.F. (2001) General Phonetics: Textbook. - Moscow : Russian State Humanitarian university, 2001. - 592 p. - (In Russ.)

18. Korb, A. (2015) The Upward spiral. Using Neuroscience to Reverse the Course of Depression, One Small Change at a Time. 2015 by Alex Korb and New Harbinger Publications, 5674 Shattuck Avenue, Oakland, CA 94609

19. Leontiev, A.N. (2005) Activity. Conscience. Personality. - Moscow : Meaning, Academy, 2005. - 352 p. - (In Russ.)

20. Mishankina, N.A. Metaphorical models of sound in the Russian language picture of the world. - http://huminf.tsu.ru/nir/attached/metmodzvuch.pdf - (In Russ.)

21. Panksepp, J. (1998). Affective Neuroscience: The Foundations of Human and Animal Emotions. New York: Oxford University Press. -466 p. 
22.

Polyakov

School.

http://www.psyworld.ru/students/lessons/lessons_text/patopsihologiya/shkola_polyacova.htm (In Russ.)

23. Propp, V.Ya. Morphology of a fairy tale. - http://filegiver.com/free-download/proppmorfologiya-volshebnoy-skazki.fb2 - (In Russ.)

24. Puzyrev, A.V., Shadrina, E.U. Theory of anagrams F. de Saussure as presented by J. Starobinsky. http://puzyrev-a-v.ru/?q=content/теория-анаграмм-ф-де-соссюра-в-изложениижстаробинского - (In Russ.)

25. Shatova, I.N. (2010) The history of the Century in the grotesque world of K. Vaginov (anagrammatic analysis of the story "The Star of Bethlehem") // Writer and Time: forms of dialogue: Materials of the XV Sheshukov readings. - Moscow: Intellect Center, 2010. - pp. 157164. - (In Russ.)

26. Tayanova, T.A. (2005) Boris Pasternak's poem "Blizzard" (1914): questions and answers // Russian Literature of the XX century. Typological aspects of the study: Materials of the X Sheshukov readings.- Moscow : Intellect Center, 2005. - pp. 406-411. (In Russ.)

27. Tolstaya, S. The phenomenon of Zaliznyak. - http://elementy.ru/nauchnopopulyarnaya_biblioteka/433935/Fenomen_Zaliznyaka - (In Russ.)

28. Volkov, S. I read the final works of students. https://web.facebook.com/sergej.lupus? tn $=\% 2 \mathrm{CdCH}-\mathrm{R}$ -

R\&eid=ARCkGvhBTuYzvSNErY4Rq7ogENS1ssPh0LzGpoLgcmvqKneBA5403HcC8S2ivG0VofIQSfF22VyyA9e Z\&hc_ref=ARSOZInB543j_xEV17D8ri-HFtQMgevQIJiyaq5eMtyiTmGL8E70KMwI9w-w-Q_5IBk\&fref=nf (In Russ.)

29. Webster, J.P., Lamberton, P.H.L., Donnelly, C.A., Torrey, E.F. (2006) Parasites as Causative Agents of Human Affective Disorders \& Proceeding of the Royal Society B: Biological Sciences, 273, pp. 1023-1030. http://dx.doi.org/10.1098/rspb

30. Wermke, K., Teiser, J., Yovsi, E., Kohlenberg, P-J., Wermke, P., Robb, M., Keller, H., Lamm, B., (2016) Fundamental frequency variation within neonatal crying: Does ambient language matter? http://dx.doi.org/10.1080/2050571X.2016.1187903

31.Yuzefovich, M.V. In memory of Pushkin. - http://pushkinlit.ru/pushkin/vospominaniya/vospominaniya-78.htm - (In Russ.) 